\title{
A (RE)CATEGORIZAÇÃO LEXICAL COMO PROPULSORA DAS ORIENTAÇÕES ARGUMENTATIVAS NO TEXTO
}

\section{THE LEXICAL (RE)CATEGORIZATION AS A PROPELLER OF ARGUMENTATIVE ORIENTATION IN THE TEXT}

\author{
Yasmin Cibelle Soares da Silva Alves" \\ Maria Teresa Tedesco Vilardo Abreu*
}

\begin{abstract}
Resumo: Tem-se como objetivo analisar de que forma ocorrem as orientações de argumentação, motivados pelo uso de marcas de referenciação no discurso, em especial pelas (re)categorizações lexicais realizadas por expressões nominais, um dos cernes propulsores para compreensão textual. Entende-se que essas marcas de referenciação podem reforçar aspectos de argumentatividade, que marcam a posição do produtor do texto argumentativo. Para tanto, a fim de analisar a estrutura da argumentação, tem-se como referencial teórico as obras de Perelman e Olbrechts-Tyteca (1999), Abreu (2005) e Fiorin (2017). No que tange à referenciação, fundamenta-se em Koch $(2004,2011,2015)$ e em Cavalcante (2005). A análise proposta evidencia que as escolhas das (re)categorizações lexicais viabilizam as (re)construções dos referentes, permitindo observar a condução dada no processo de construção do texto por seu produtor, que almeja persuadir seu público. Os recursos textuais, presentificados na materialidade linguística, deixam pistas argumentativas que vão sendo (re)construídas pelo leitor

Palavras-chave: Argumentação. (Re)categorização lexical. Orientações argumentativas.
\end{abstract}

\begin{abstract}
The objective is to analyse how argumentative orientations occur, motivated by using marks of referencing in discourse, especially for lexical recategorization performed by nominal expressions, one of the propellant cores for text comprehension. Those referecing marks can strengthen argumentative aspects, that mark the position of the argumentative text's author. For this purpose, in order to analyse the argumentative structure, it's considered as theoretical referencial the works of Perelman and OlbrechtsTyteca (1999), Abreu (2005) and Fiorin (2007). In what concerns referrencing, it's based on Koch (2004, 2011, 2015) and Cavalcante (2005). The proposed analysis reveals that the choices of the lexical recategorizations facilitate the reconstruction of the references, permiting to observe the directions in the text construction by its producer, that aims persuade his audience. Text resources, presented in liguistic materiality, leave argumentative clues that are rebuilding by the reader.
\end{abstract}

Keywords: Objects of argumentation. Lexical Recategorization. Argumentative orientations.

\section{Introdução}

$\mathrm{O}$ encaminhamento dado às orientações argumentativas pelo autor do texto para alcançar a adesão de seu público, pode ser observado a partir de sinalizadores na superfície linguística, que vão muito além das conjunções e das locuções conjuntivas que trazem, de maneira explícita, o encadeamento das relações lógicas do texto. Tais orientações podem estar marcadas na materialidade linguística da qual a linguagem em si não foge para se instaurar, a referenciação, uma vez que sempre falamos de algo em um conjunto de referências. Em razão disso, o enfoque é dado para as (re)categorizações lexicais realizadas por expressões nominais que estejam necessariamente ancoradas no cotexto.

\footnotetext{
* Mestranda em Descrição da Língua Portuguesa pela Universidade do Estado do Rio de Janeiro e bolsista da Coordenação de Aperfeiçoamento de Pessoal de Nível Superior (CAPES). Email: cibellessalves@gmail.com

** Professora associada de Língua Portuguesa no Instituto de Letras da Universidade do Estado do Rio de Janeiro (UERJ). Pós-Doutora em Linguística pela Universidade de Colônia, Alemanha (2017). Doutora em linguística pela UFRJ (2002); Mestre em linguística pela UFRJ (1992); especialista em Linguística Aplicada pela UERJ (1989). Email: teresatedesco@uol.com.br
} 
Nesse sentido, por meio dos aportes da argumentação e da retórica, vistas pelo viés do Tratado da Argumentação: a Nova Retórica (1999) e de autores que bebem nessa fonte, como, Abreu (2005) e Fiorin (2017), aliados aos referencias teóricos da Linguística Textual sobre referenciação à luz das autoras Koch $(2004,2015)$ e Cavalcante (2005), que nos dão embasamento teórico-metodológico, buscamos desvendar como a construção e a reconstrução dos referentes, na dinâmica discursiva, indiciam e encaminham certos valores que recaem em determinados lugares de argumentação. Por meio disso, torna-se viável verificar como se configuram as hierarquias desses valores no discurso do argumentador para convencer ou persuadir seu público. Para tanto, por fim, a análise sobre dois artigos de opinião do jornal O Globo.

\section{Fundamentação Teórico-metodológica}

\subsection{Argumentatividade e argumentação no discurso}

Perceber a língua como mediadora de nossa relação com a realidade, e não como mero mecanismo de etiquetagem desta nos proporciona ver tal mediação como a viabilizadora de nossa atuação sobre o mundo e de nossa interação com ele. Por essa razão, cabe o entendimento de Austin (1975) de que ao falarmos, agimos, pois, nas interações sociais, buscamos influenciar o outro para que este (com)partilhe de nossas percepções sobre o mundo, sobre o nosso universo referencial. Manifestamos, em decorrência disso, constantemente nossas avaliações, crenças, juízos de valor em um jogo de (inter)subjetividades. Nesse sentido, a língua em uso revela seu caráter intrínseco: a argumentatividade. Imbuída dessa compreensão, Koch afirma que o ato de argumentar se constitui como um ato fundamental, pois a todo e qualquer discurso está subjacente uma ideologia, "a neutralidade é apenas um mito: o discurso que se prende ao "neutro", ingênuo, contém também uma ideologia - a da sua própria objetividade" (KOCH, 2011, p. 17).

Todavia, há a necessidade de se fazer um esclarecimento importante sobre a diferença entre argumentatividade e argumentação, conforme Conforte (2012, p.259) nos chama atenção

\footnotetext{
Ressalve-se que tratar do que chamamos argumentação significa tratar de aspectos muito amplos da linguagem humana, uma vez que parece haver consenso de que a argumentatividade está incrustada em toda a linguagem - embora não se deva, a partir disso, dizer que "todo enunciado é, portanto, argumentativo", pois se trata de uma conclusão falaciosa: uma coisa são os objetivos da comunicação humana, outra é a estrutura linguística e semântica de nossos enunciados, muito embora a própria iconicidade da linguagem tente sempre dar conta de vincular um aspecto ao outro - mas nem sempre consiga.
}

Observada essa ressalva, propomo-nos a trabalhar com a argumentação vista à luz do Tratado da Argumentação: a Nova Retórica, obra de Perelman e OlbrechtsTyteca (1999) que propuseram a Nova Retórica, concepção argumentativa e retórica sob a qual este trabalho se alinha.

A partir dessa percepção, destacamos que a argumentação, segundo Perelman e Olbrechts-Tyteca (1999, p. 16), tem como propósito "provocar ou aumentar a adesão de espíritos e, por isso mesmo, pressupõe a existência de um contato intelectual". Na atividade de argumentar, instauram-se um orador, quem argumenta, e um auditório, os "espíritos" que o orador busca influenciar com sua argumentação. É importante observar que a atividade argumentativa é discursiva e interativa, uma vez 
que é determinada pelo orador, o produtor do texto, que, ao elaborar sua argumentação, considera o outro, seu interlocutor.

Com isso, podemos verificar que a argumentação não se erige de modo unilateral, sendo uma atividade interativa na qual se estabelecem jogos intersubjetivos, pois "tanto o desenvolvimento como o ponto de partida da argumentação pressupõem acordo do auditório" (PERELMAN; OLBRECHTSTYTECA, p. 73), o orador funda seu projeto de dizer que se delineia em uma perspectiva retórica e pragmática, visando seu auditório. A fim de que seja eficaz, a argumentação depende de variados fatores, tais como, a credibilidade que o orador apresenta e forma em seu discurso e o apreço dele pela adesão de seu auditório, caracterizando-o a partir de suas convicções dominantes. Além disso, cabe reconhecer que, na argumentação, se distinguem os atos de convencer e os de persuadir. Aquele se relaciona com o saber gerenciar informação, é falar a razão do outro, demonstrando, provando, por sua vez, persuadir trata-se de saber gerenciar a relação, é falar à emoção do outro (cf. ABREU, 2005).

Dito isso, é fundamental nos atermos à formação do auditório pelos postulados da Nova Retórica que propõe a existência do auditório universal e do auditório particular. Para tanto, tomemos as explanações de Abreu $(2005$, p.42) que, imbuído da concepção de Perelman e Olbrechts-Tyteca (1999), explica e exemplifica que o auditório universal é constituído por um conjunto de pessoas heterogêneas, de diferentes idades, profissões, cultura, etc., tal como, o público que assiste um programa de televisão. Por sua vez, o auditório particular tem varáveis mais controladas, tal como, uma turma de alunas de uma escola de segundo grau configura um auditório particular. Trata-se de pessoas jovens, do sexo feminino, com o mesmo nível de escolaridade. A partir desses dois tipos de auditórios, são firmados os dois objetos de acordos os quais estabelecem a argumentação que podem se erigir pelas categorias referentes ao real e ao preferível.

Os tipos de objetos de acordo pertencentes ao real, que pretendem a adesão do auditório universal são os fatos, as verdades e as presunções. Os dois primeiros objetos podem se destacar por não gerar a necessidade de justificativa, pois parte de uma reação subjetiva a algo que se impõe a todos. Entretanto, ainda, as verdades se particularizam pelo modo como se concebem os fatos, podendo estar atreladas às concepções que transcendem à experiência, como, a concepção filosófica e a religiosa, de acordo com Perelman e Olbrechts-Tyteca (1999, p. 77). Por fim, as presunções precisam que a adesão seja reforçada, já que a adesão não é máxima por se fundamentarem naquilo que é normal.

Ao lado dos objetos de acordo pautados no real, há outros objetos sobre os quais debruçamo-nos neste trabalho, visto que pretendem apenas a adesão de grupos particulares: os valores, as hierarquias e os lugares que são fundados objetos de acordo do preferível, ligados a um ponto de vista. Sendo assim, os valores, um dos objetos de acordo de uma argumentação pautados no preferível "são balizas morais que uma dada sociedade numa determinada época considera como verdade" (FIORIN, 2005, p. 200). Como exemplos disso, temos valores como justiça, veracidade, solidariedade, Igreja, França, sendo os três primeiros de conceituação mais imprecisa, abstrata, e o restante concebido mais concretamente. Por intermédio de múltiplos valores, motiva-se o interlocutor a fazer certas escolhas no lugar de outras, principalmente para torná-las aceitáveis e aprováveis.

As hierarquias de valores pressupõem a superioridade de algo pautadas em valores, como, por exemplo, a superioridade do homem sobre as coisas. Certamente, as pessoas têm seus valores em escalas de importância diferentes, logo, o modo como o 
auditório hierarquiza os seus valores chega a ser, às vezes, até mais importante do que os próprios valores em si (cf. ABREU, 2005). Por fim, os lugares da argumentação, na proposta de Perelman e Olbrechts-Tyteca (1999) podem permitir fundar valores e hierarquia. Tratam-se de premissas mais gerais, subentendidas que justificam a maior parte de nossas escolhas, segundo os autores do Tratado da Argumentação (1999, p. 95). Podemos observar que os lugares da argumentação podem equivaler aos valores predominantes escolhidos pelo orador na prática argumentativa. Ampliando essa observação, podemos dizer que esses lugares podem caracterizar sociedades porque elas concedem uma intensidade de adesão a este ou àquele membro de um par de lugares antitéticos, segundo os autores supracitados. Não importa qual for o auditório, todos levam em conta os lugares em que se pauta a argumentação, visto que na prática argumentativa são relevantes, pois esta prática não se insere em contextos vazios.

Por conseguinte, decerto, cabe destacar que os valores na argumentação possibilitam a comunhão sobre os modos de agir, estão vinculados à multiplicidade de grupos (cf. PERELMAN; OLBRECHTS-TYTECA, 2005). São, assim, crenças, ideologias que incorrem a lugares de argumentação, delineados por premissas mais gerais, sendo voláteis no tempo, espaço, cultura e sociedade, portanto, podem caracterizar uma sociedade. Os valores têm como base "justificar escolhas sobre as quais não há acordo unânime, inserindo essas escolhas numa espécie de contexto vazio, mas sobre o qual reina um acordo mais amplo" (PERELMAN; OLBRECHTSTYTECA, 2005, p. 86). Então, a medida que os acordos que podem ser aderidos pelo auditório universal, passam a ser especificados e limitados, passam a ter o acolhimento de um auditório particular.

Dada essa noção geral, é pertinente expor quais seriam os lugares da argumentação. Estes, de acordo com Abreu (2005), desdobram-se em seis: lugar de quantidade, lugar de qualidade, lugar de ordem, lugar de essência, lugar de pessoa, lugar do existente. O lugar de quantidade se fixa na ideia de "qualquer coisa vale mais que outra em função de razões quantitativas." (2005, p. 81), logo, um bem que serve um grande número de pessoas tem mais valor do que um bem que atenda menos pessoas. No sentido inverso, o lugar de qualidade prima pelo único, pelo singular, tal como exemplifica Abreu (2005, p. 84) pelo valor de um cão de estimação, há vários cães no mundo, mas o de estimação torna-se único para quem pertence. Como o nome já sugere, o lugar de ordem se configura pela hierarquização dada a partir, por exemplo, da superioridade do anterior sobre o posterior, das causas sobre os efeitos, dos princípios sobre as finalidades.

Por sua vez, Abreu (cf. 2005, p. 90) explica e ilustra que o lugar de essência valoriza indivíduos como representantes bem caracterizados de uma essência, como, por exemplo, a eleição de uma miss por representar a essência de uma mulher bonita. Já o lugar de pessoa é "O lugar de pessoa afirma a superioridade daquilo que está ligado às pessoas. Primeiro as pessoas, depois as coisas! é o slogan que materializa esse lugar" (ABREU, 2005, p. 92 ). Por fim, o lugar do existente é o lugar em que se dá preferência ao que já existe. Por meio dessa exposição, é válido reiterar para os objetivos do nosso trabalho que, a partir dos lugares em que se configuram a argumentação podemos fundar os nossos valores e suas respectivas hierarquias que permitem justificar a tese e as opiniões expostas no discurso.

\subsection{As evidências da argumentação na atividade textual-discursiva como construção de sentido: um lugar para a referenciação}


Ao longo da exposição deste trabalho, vimos que a interação social por intermédio da língua caracteriza-se pela argumentatividade, em conformidade com Koch (2015), a fim de que (com)partilhemos de nossas percepções sobre as "coisas" no mundo. Logo, em todo discurso, faz-se presente a argumentatividade em maior ou menor grau, nos interessando aqui os discursos em que esta se manifesta com maior intensidade, ou seja, nos discursos que são organizados predominantemente pela argumentação. Em razão disso, torna-se relevante, de igual maneira, observar o encaminhamento do nosso processo de argumentar e de significar nas e pelas marcas linguísticas que registram as orientações argumentativas por meio da (re)construção dos referentes do discurso. Tal construção, por conseguinte, trata-se de um processo do qual a linguagem não foge para se consolidar, pois sempre falamos alguma coisa em conjunto de referências (BENVENISTE, 1995).

Devido a sua essencialidade na linguagem, a atividade de referenciar se tornou um tema notório dentro do campo dos estudos linguísticos, sobretudo na Linguística Textual. Vinculada à argumentação, em tal atividade, subjazem as intencionalidades, os valores, no discurso, para configurar os referentes os quais designam as entidades manipuladas por nossa percepção de realidade nas e pelas marcas linguísticas. Nesse sentido, no processo de referenciar, os referentes, tidos como objetos de discurso, se (re)constroem na dinâmica da interação, vão sendo retomados e (re)construídos, vão conferindo a manutenção, a progressão e a construção de sentido no discurso.

Dessa forma, a referenciação é uma atividade de significar o mundo, o que se torna patente nos dois fenômenos da referenciação: a categorização e a recategorização. Segundo as palavras de Mondada e Dubois (2003, p. 22), no primeiro fenômeno, entende-se que

as categorias utilizadas para descrever o mundo mudam, por sua vez, sincrônica e diacronicamente: quer seja em discursos comuns ou em discursos científicos, elas são múltiplas e inconscientes; são controversas antes de serem fixadas normativa ou historicamente.

Tal mudança apresenta-se na maneira particular de perceber e conhecer o mundo, o que em certa medida é compartilhado, coincide com uma percepção geral, isto é, uma cognição social (DIJK, 2012)

De maneira complementar, a recategorização seria a transformação da representação pela qual o referente passa ao longo da atividade discursiva, a menor ou maior desestabilização da categoria em mudança é o próprio traço, explícito ou implícito, que define a recategorização de um referente, quer tenha ele sido já introduzido no discurso para ser transformado, quer não tenha sido e se recategorize apenas mentalmente, no próprio momento em que o anafórico remete indiretamente à sua âncora. (cf. CAVALCANTE, 2005).

Com isso, percebe-se que esse fenômeno não se limita ao nível discursivotextual, mas também se configura na mente, contribuindo para a construção da significação feita e ativada pelas escolhas do material linguístico do texto, o cotexto, que vão encadeando uma orientação de intencionalidade ao discurso, em que se recria o texto através da mediação de nossas perspectivas e visões de mundo ( $\mathrm{KOCH}$; TRAVAGLIA, p. 98). Portanto, esse fenômeno textual-discursivo registra o projeto de dizer e orienta a aceitação, isto é, a compreensão do texto.

Sendo assim, no texto, fica claro que, quando se (re)constrói o referente, há uma seleção de características pelas quais se busca defini-lo em alguma categoria ou lugar. As entidades têm de ser conhecidas ou se tornar conhecidas para serem passíveis de recuperação. Estas, dessa forma, também podem ser inferidas pelo nosso conhecimento 
de mundo na situação comunicativa. Por esse motivo, Perelman e Olbrechts-Tyteca (1999) afirmam que "toda argumentação supõe, portanto, uma escolha que consiste não só na seleção dos elementos que são utilizados, mas também na técnica da apresentação destes" (p. 136), dando continuidade ao esclarecimento, entendem que "por vezes ela (a escolha dos termos) servirá mais diretamente à argumentação, situando o objeto de discurso numa categoria [...] (p. 169)

Desse modo, a seleção dos termos não é ingênua, o que pode ser um fato observável na (re)categorização lexical, ainda pelas anáforas nominais, formas remissivas que dão conta de manifestar essa intencionalidade, uma vez que são escolhas, na maioria das vezes, subjetivas, já que são utilizadas palavras de significação extralinguísticas que "são símbolos substitutos e interpretativo das coisas", segundo Kebrat-Orecchioni (1986, p. 91). Para Koch (2011) a seleção lexical é um recurso retórico de grande importância, já que há palavras que, colocadas estrategicamente no texto, trazem consigo uma carga poderosa de implícitos (p. 151). Por esse motivo, o recorte de nosso objeto de estudo incide na análise do fenômeno da (re)construção dos referentes por expressões nominais, dentro da dinâmica discursiva, em que são selecionadas e ativadas propriedades do referente para caracterizá-lo de modo que, potencialmente, pode revelar, de forma implícita ou explícita, informações importantes acerca dos valores do orador e, consequentemente, as hierarquias e os lugares da argumentação em que estão postos esses valores.

Dentro desses recursos de (re)construções do referente por itens nominais, isto é, de (re)categorizações lexical, as expressões nominais que as compõem podem ser definidas e indefinidas a fim de percebermos como se articula o encaminhamento dos valores. Primeiramente, podemos nos ater a constituição linguística dessas expressões que se apresentam por meio de um determinante definido e/ou um modificador seguido de um nome, descrição definida, e, por sua vez, descrição indefina a que tem seu determinante indefinido, sendo menos explorada pelos estudiosos, segundo Koch (2004).

Assim, de acordo com Koch (2015, p. 73) as descrições definidas como recurso de recategorização do referente se caracteriza por "operar uma seleção dentre as diversas propriedades do referente - reais, co(n)textualemente determinadas ou intencionalmente atribuídas pelo locutor [...]”. Ademais, ao se utilizar de uma descrição definida se incorre em escolhas frente as propriedades ou qualidades possíveis para caracterizar o referente, em função do projeto de dizer do produtor do texto. Portanto, "trata-se, em geral, da ativação dentre conhecimentos pressupostos como compartilhados com o(s) interlocutor(es) [...], de características ou traços do referente que o locutor procura ressaltar" $(\mathrm{KOCH}, 2015, \mathrm{p}$. 74). Tais escolhas trazem à tona informações importantes sobre as opiniões, crenças e atitudes do produtor do texto, por outro lado, o locutor, quem fala, também pode ter o objetivo de dar a conhecer informações sobre o referente.

Cabe observar que, para essas expressões nominais referenciais utilizadas como estratégias de (re)categorização, há as funções discursivas, textuais e cognitivas. Dentre essas funções, encontramos a nominalização composta por "substantivo predicativo ao lexema utilizado como nome-núcleo dessa construção" (KOCH, 2015, p. 73). Pode ainda haver nominalização sem determinante em casos que o nome-núcleo vem acompanhado de um modificador, em forma de oração relativa geralmente ou em casos em que seguido do demonstrativo ou de um indefinido, bem como, ainda, de uma estrutura comparativa. Discursiva e cognitivamente, essa operação pode se erigir como uma sumarização, um encapsulamento de uma informação precedente, transformandoas em objetos de discurso. São, desse modo, anáforas "complexas" que não nomeiam 
um referente específico, mas referentes abstratos que retratam um estado, fato, evento, atividade, etc., segundo a autora. Ademais, devido à complexidade dessas anáforas, podem ainda demandar de uma capacidade de interpretação de informação adicional, uma vez que rotulam parte do cotexto precedente, estabelecendo um novo referente que pode contribuir para os enunciados subsequentes $(\mathrm{KOCH}, 2015$, p. 76)

Com isso, observamos que a seleção dos termos tanto para a categorização quanto para a recategorização lexical a fim de se firmar a caracterização do referente o coloca em uma categoria, operando uma representação do estado das coisas, do qual parte de uma intenção argumentativa na qual subjazem os valores do que o orador prima. Em consequência disso, os argumentos, por sua vez, partem de categorias, de lugares como vimos na seção anterior, o que permite perceber a intenção do orador e como quer direcionar a compreensão do auditório.

\section{Análise de Corpus}

Partindo para a aplicação da proposta de nos debruçarmos nas marcas linguísticas da (re)categorização pelas expressões nominais que compõem as descrições definidas e indefinidas com intuito de observarmos como podem dar e registrar o encaminhamento das orientações argumentativas, inclinamo-nos sobre as formas remissivas nominais ancoradas no cotexto. Dessa forma, observaremos dois textos que giram em torno de um mesmo tema, um assunto polêmico, o casamento entre duas pessoas do mesmo sexo sob o ponto de vista judaico, contudo, cada texto manifesta uma visão diferente. Os textos trabalhados são artigos de opinião publicados no jornal $O$ Globo, da coluna Opinião, do mês de março de 2018, motivados por um acontecimento histórico no hotel mais prestigiado da cidade do Rio de Janeiro: o primeiro casamento entre duas mulheres judias no Copacabana Palace.

Apresentado o fato motivador dos dois artigo de opinião, a primeira abordagem é dada pelo rabino Yehoshua Goldman no texto intitulado Por que se casar?, datado em 17 de março de 2018. Nesse artigo de opinião, não é mencionada a motivação do assunto tampouco faz referência explícita a ela. Entretanto, a motivação fica evidente por justamente uma semana após o casamento entre duas judias o rabino escrever um texto em que considera legítimo apenas o casamento entre um homem e uma mulher, afirmando ser este o ponto de vista do judaísmo. O texto de Goldman é exposto por meio de uma narrativa que se funda na busca de certos jovens estudantes por saber sobre as diferentes perspectivas de líderes religiosos sobre o que é o casamento, até que esses jovens procuram saber a visão do judaísmo. Tal visão judaica sobre o casamento é construída ao longo da narrativa de maneira contrária ao casamento de pessoas do mesmo sexo, conforme analisaremos adiante.

Podemos observar, no artigo de Goldman, a princípio, a relevância do modo como se introduzem e se categorizam os objetos de discurso para a construção o projeto de dizer do autor ao longo do texto e, consequentemente, para o encaminhamento argumentativo. Nesse sentido, vale determos a atenção ao no primeiro parágrafo que segue abaixo.

\footnotetext{
"Os jovens universitários de uma cidade tradicional e conservadora resolveram chamar um rabino para lhes falar sobre casamento. Como já tinham ouvido outros líderes espirituais, ficaram curiosos em saber qual é o ponto de vista da tradição judaica sobre casamento." (grifos nossos)
}

Observando os termos grifados do primeiro parágrafo, é notória a introdução do objeto de discurso "Os jovens universitários de uma cidade tradicional e conservadora" 
realizado por uma descrição definida. Essa descrição diz respeito aos jovens que motivaram a discussão sobre o casamento com o rabino e estes são descritos como sendo jovens de uma cidade tradicional conservadora. Tais caracterizações dos jovens alocam informações que contribuem muito para entender o modo que esses jovens entendem o assunto em foco, o casamento, e quais são os seus valores. Por sua vez, "um rabino" é um termo de sentido específico que é retomado por uma expressão mais genérica, como sendo parte pertencente do conjunto de "outros líderes espirituais". Assim, mesmo que o leitor não saiba o que é um rabino, saberá que se um líder espiritual de uma determinada religião, logo, o autor permite dar a conhecer tal expressão a seus leitores, o seu auditório. Além disso, é de grande valia observar que foi selecionado o termo "líder espiritual", logo, trata-se uma autoridade que discorrerá sobre o assunto proposto.

A narrativa continua com o rabino questionando "Vocês não sabem que hoje em dia não precisa se casar?", em resposta a curiosidade dos jovens que o questionaram sobre o casamento. Essa questão gera a reação de um componente do conjunto do primeiro objeto de discurso do texto, "um dos estudantes" o qual tem seu estado descrito como estando "surpreso" e "indignado". Essas descrições que fazem referência a "um dos estudantes" se tratam de predicações, mas não apenas isso, é uma reconstrução do referente, apresentando o seu estado diante da assertiva do rabino. Por isso, o processo de predicação não se limita ao nível da sintaxe, mas o extrapola, pois

[...] as expressões referenciais nominais exercerem, em grande número de casos, uma dupla função cognitivodiscursiva (cf. Koch, 2002), isto é, que ao mesmo tempo em que reativam referentes já presentes na memória discursiva, elas introduzem novas predicações a respeito deles (KOCH, 2004, p. 7)

A descrição dessa reação e os itens lexicais escolhidos para tal reforçam a ideia de que essa seria uma reação provável de jovens provenientes de uma cidade que se funda em valores tradicionais e conservadores, uma vez que nessas predicações o enunciador não quis apenas atribuir predicações, mas sim construir seus objetos-dediscurso por meio de expressões nominais, o que é, inclusive, retoricamente muito mais ágil e mais forte. (cf. KOCH, 2004)

Além dessa reação, outra ocorre corroborando a leitura feita acima de que os universitários estavam imbuídos dos valores da cidade que pertenciam, porque outra personagem da narrativa, também estudante questiona: "Mas rabino, casamento é estabilidade, segurança! A certeza de que alguém estará sempre ao seu lado, lhe dando apoio e sustento, ajudando com as contas do lar!". Pelo que foi grifado, podemos perceber, novamente, uma predicação, mas que diz respeito às propriedades do objeto de discurso "casamento" selecionadas pela estudante que proferiu, o implica na crença de que os valores fundantes dessa instituição social são a estabilidade e a segurança. Desse modo, ao observarmos a perspectiva dos componentes do conjunto "os jovens universitários de uma cidade tradicional e conservadora" que são descritas pelo narrador que é o produtor do texto, percebemos que esses jovens estudantes recaem em um conjunto de crenças, avaliações que se figuram tradicionais e conservadoras.

Por outro lado, o rabino, no decorrer de sua narrativa, tende a ter uma concepção que é diferente do ponto de vista de dos jovens, parece ser menos conservador, já que refuta os motivos dados pelos jovens para se casar. Um exemplo da concepção contrária do rabino se dá no momento em que recategoriza os valores apresentados envolvidos no casamento, como a segurança e a estabilidade homologado em "um contrato de responsabilidade mútua" que, nos tempos atuais, torna desnecessário o casamento. Por 
esses elementos, parece que o rabino, se opondo a perspectiva dos jovens de valores tradicionais e conservadores, encaminha-se para o sentido oposto: uma concepção nova e moderna. Todavia, a concepção do rabino de casamento funda-se em valores, preceitos que afirma ser da religião judaica, uma vez que ao ser questionado do porquê se casou responde:

Eu me casei porque o casamento é um mandamento divino. Foi o Criador que ordenou aos ancestrais de toda a humanidade, Adão e Eva, a se casar (como consta em Genesis 1:24) — e não só para ter companheirismo, amor, estabilidade, segurança, intimidade ou um lar para os meus filhos. Eu me casei porque o casamento é sagrado, é uma união divina! Não é uma mera formalidade humana... Essa é a milenar tradição judaica do conceito de casamento. ( grifos nossos)

A partir da análise das expressões nominais referenciais, observamos que os argumentos contrários do líder religioso se fixam em os valores de casamento compreendidos como se estivessem em um plano superior, transcendental, segundo indica a predicação "sagrado" e a reconstrução por uma descrição indefinida "uma união divina". Pode-se perceber que os argumentos são balizados no lugar da ordem, pois a recategorização "aos ancestrais de toda a humanidade" de Adão e Eva que remete a ordem e a formação da instituição primeira do casamento. Com isso, o rabino tenta desconstruir os valores manifestados pelos jovens sobre o casamento ao longo do texto, como, "companheirismo, amor, estabilidade, segurança, intimidade ou um lar para os meus filhos". Tais valores, realizados no texto por expressões definidas, são recategorizados pelo rabino por meio da descrição indefinida "uma mera formalidade humana". Por fim, o rabino arremata seu texto com "Essa é a milenar tradição judaica do conceito de casamento" que sumariza as informações tratadas nesse parágrafo, encapsulando-as, o que nos faz resgatar também que foi dado "o ponto de vista da tradição judaica sobre o casamento" no início do artigo.

Por fim, o argumento principal do rabino emerge da valoração do ser "Criador do universo", reforçando no penúltimo parágrafo que "o casamento não é um conceito humano; é uma ideia divina". Por esse motivo, no último parágrafo, "o conceito de casamento é sagrado", pois foi estipulado pelo ser superior aos homens, Deus. Diante disso, Perelaman e Olbrechts-Tyteca $(1999$, p. 88) ressaltam que "raciocínios referentes a Deus, considerado, a um só tempo, valor abstrato absoluto e Ser perfeito", portanto, tudo que Deus faz é correto e bom, como, estipular o casamento entre um homem e uma mulher. Em virtude disso, o que está sendo sustendo, de maneira implícita, está no campo do preferível, pautado em uma hierarquia dominante do valor abstrato centrado no lugar de essência, Deus, visto que, na visão do rabino, o casamento entre pessoas do mesmo sexo não é bom nem correto porque não foi o que Deus estipulou.

O texto do rabino Goldman, por isso, abrange um auditório particular por ser ligar a um ponto de vista que, evidentemente, hoje em dia não é unânime, tanto é assim que Keila Grinberg, também judia, rebate o rabino no artigo de opinião Todo Amor é Sagrado, publicado dia 22 de março de 2018. Neste artigo de opinião, a autora, que claramente estabelece uma relação dialógica com o texto de Goldman, introduz afirmando que

Uma das características mais fascinantes do judaísmo é o fato de ser uma religião com poucos dogmas. Para além do monoteísmo (Deus existe e é um), não há praticamente nenhum tema que nunca tenha sido questionado. Há séculos os judeus vêm debatendo e transformando suas tradições. Como não existe entre nós uma 
autoridade central que tenha a última palavra sobre os assuntos da religião, o famoso ditado "se há dois judeus, haverá três opiniões", mais que uma piada interna, é uma perfeita expressão da pluralidade judaica. (grifos nossos)

Tendo isso em vista, podemos verificar que a introdução do referente "Uma das características mais fascinantes do judaísmo" é recategorizado, qualificado como "uma religião com poucos dogmas". Isso nos permite ressaltar a abrangência e a diversidade como propriedades inerentes ao judaísmo. Por isso, convergindo para essa constatação, a autora diz que há "o famoso ditado", categorizado com valor positivo para o que contrapõe, declarando, pela recategorização por descrição indefinida "uma perfeita expressão da pluralidade judaica", sendo essa a essência do judaísmo, "uma das características mais fascinantes do judaísmo".

De maneira similar, no segundo parágrafo a autora continua reiterando a essência do judaísmo: "O resultado disso é que a divergência é parte essencial do judaísmo. E quem sabe não seja essa capacidade de transformar e adaptar a tradição a razão da sua sobrevivência ao longo dos tempos?". Esta recategorização por uma descrição definida dada a partir de um questionamento sumariza as informações do que foi falado anteriormente, o que ativa o conhecimento compartilhado de que os judeus são um dos povos, uma das culturas vivas mais antigas da história da humanidade. Isso vem contribuir significativamente para o projeto de dizer da autora que busca rebater o rabino Goldman pelo argumento pautado no valor positivo da singularidade do juidaísmo, podendo até mesmo atribuir a sua sobrevivência na História por conta dessa característica.

No quarto parágrafo, Grinberg explana que "A posição de Goldman é legítima e fundamentada num ramo da ortodoxia judaica. Mas faltou esclarecer aos leitores que este ponto de vista exposto no artigo é o dele, o da sua congregação, da corrente à qual se filia.". Nesse parágrafo, consta a recategorização do referente "a posição de Goldman" é feita por uma descrição indefinida "num ramo da ortodoxia judaica", o que saliente o caráter partitivo dessa posição, pois é um ramo dentre outros no conjunto em que se constitui o judaísmo. Em seguida, a descrição definida "este ponto de vista exposto no artigo é o dele, o da sua congregação, da corrente à qual se filia" mais uma vez reitera e sintetiza a informação da fundamentação da perspectiva judaica do rabino Goldman sobre o casamento, reforçando que sua perspectiva sobre o tema se manifesta de forma unilateral.

A partir disso, a autora introduz uma quantidade considerável de objetos de discurso por expressões nominais em seu texto, como, a "World Union for Progressive Judaism", citada no quito parágrafo, que arremata a enumeração de relatos sobre a aceitação e a realização de casamento entre pessoas do mesmo sexo em variadas tendências judaicas. Essa estratégia utilizada pela autora em sua contra-argumentação se fixa em valores concretos e continua os utilizando no sexto parágrafo, dando primazia ao lugar de quantidade de ocorrências de aceitação do casamento homossexual no meio judaico para sustentar sua argumentação, pois "13 organizações judaicas, incluindo grupos religiosos, apoiaram a petição em favor do casamento entre pessoas do mesmo sexo".

Então, de forma explicitamente dialógica, Grinberg declara que "todo amor é sagrado rabino. Que cada um ame quem quiser e, se quiser, que case". Essa declaração faz referência ao último parágrafo do texto de Goldman "O conceito de "casamento" é sagrado: Não devemos profaná-lo". Dessa maneira, no último parágrafo, a autora judia conclui que "As divergências entre nós são tão possíveis quanto saudáveis. Não 
vamos perder essa oportunidade.", sendo essa última expressão grifada um encapsulamento nominal do qual emerge o valor positivo do judaísmo poder conviver com as divergências que são possíveis e saudáveis, o que é visto como uma "oportunidade".

Portanto, o projeto de dizer de Grinberg tem o propósito de mostrar o quão parcial é o que o rabino Goldman declara como "o ponto de vista da tradição judaica sobre casamento", evidenciando que essa categorização não passa apenas de um ponto de vista, de uma crença, de uma recategorização indefinida, pois, no judaísmo em geral, essa perspectiva trata-se de um ponto de vista dentre vários. A autora prioriza a autonomia do ser humano, sua dignidade e liberdade dentro do judaísmo, inserindo seus argumentos, sobretudo em valores que se circunscrevem no lugar de pessoa.

\section{Conclusão}

A partir desse estudo buscou-se refletir sobre como a argumentação que se utiliza dos objetos de acordo pautado no preferível é evidenciada por índices textuaisdiscursivas. $\mathrm{O}$ orador que é um produtor de texto apresenta seu ponto de vista no desenvolvimento de seu projeto de dizer de maneira patente na seleção que faz com as palavras, especialmente nas expressões nominais que compõem e instauram os referentes, os objetos de discurso de modo que se seja (com)partilhada sua percepção.

Nessas evidências da materialidade linguística, ancoram-se os valores do orador e, na medida em que os referentes vão sendo introduzidos e (re)contruídos em uma cadeia referencial, há uma progressão e uma manutenção do tema abordado, permitindo expressar as hierarquias desses valores e os lugares em que recaem o direcionamento argumentativo do orador para convencer seu público. Isso nos proporciona ver a argumentação como uma constante (re)categorização da percepção do mundo com intuito de se alcançar a adesão do outro, do auditório.

\section{Referências}

ABREU, A. S. A Arte de Argumentar: gerenciando razão e emoção. 8. ed. São Paulo: Cotia: Ateliê Editorial, 2005.

AUSTIN, J. L. How to do things with words. 2. ed. Oxford: Oxford University Press, 1975.

BENVENISTE, E. Problemas de lingüística geral I e II. Campinas, SP: Pontes, 1995.

CAVALCANTE, M. M. Anáfora e Dêixis: quando as retas se encontram. In: KOCH, V.; MORATO, E. M. M.; BENTES, A. C. Referenciação e Discurso. São Paulo: Contexto, 2005. p. 125-149.

CONFORTE, A. N. Argumentação e Léxico na Perspectiva da Iconicidade Verbal. Caderno Seminal Digital: Rio de Janeiro, v. 1, no 26, p. 49-76, jul. 2016. Disponível em: $<$ http://www.epublicacoes.uerj.br/index.php/cadernoseminal/article/view/27178/19663>. Acesso em: 16 ago. 2018

DIJK, T. A. Discurso e Contexto: uma abordagem sociocognitiva. Tradução de Rodolfo Ilari. São Paulo: Contexto, 2012. 
FIORIN, J. L. Argumentação. 1. ed. São Paulo: Contexto, 2017.

KERBRAT-ORECCHIONI, C. La enunciación. De la subjetividad en el lenguaje. Buenos Aires: Edicial, 1986.

KOCH, I. G. V. As Expressões Nominais Indefinidas e a Progressão Referencial. Revista de Letras, Ceará, v. 1/2, nº 26, p. 5-8. 2004. Disponível em: <http://periodicos.ufc.br/revletras/article/view/2258>. Acesso em: 15 ago. 2018.

Argumentação e Linguagem. 13. ed. São Paulo: Cortez, 2011

Introdução à linguística textual. 2. ed. São Paulo: Martins Fontes, 2015.

MONDADA, L.; DUBOIS, D. Construção dos objetos de discurso e categorização: uma abordagem dos processos de referenciação. In: CAVALCANTE, $M$. et al. Referenciação. São Paulo: Contexto, 2003.

O GLOBO. Seção Opinião. Edição de 17 de março de 2018.

O GLOBO. Seção Opinião. Edição de 22 de março de 2018.

PERELMAN, C.; OLBRECHTS-TYTECA, L. Tratado da Argumentação: a Nova Retórica. São Paulo: Martins Fontes, 1999.

Recebido em 01 de junho de 2019

Aceito em 08 de agosto de 2019 